\title{
Nitrogen Fertilization Reduces Nitrogen Fixation Activity of Diverse Diazotrophs in Switchgrass Roots
}

\author{
Rahul A. Bahulikar, ${ }^{1}$ Srinivasa R. Chaluvadi, ${ }^{2}$ Ivone Torres-Jerez, ${ }^{1}$ Jagadish Mosali, ${ }^{1}$ Jeffrey L. Bennetzen, ${ }^{2}$ and Michael Udvardi ${ }^{2, \dagger}$ \\ ${ }^{1}$ Noble Research Institute, Ardmore, OK \\ ${ }^{2}$ Department of Genetics, University of Georgia, Athens, GA
}

Accepted for publication 3 December 2019.

\section{ABSTRACT}

The use of synthetic nitrogen fertilizers to grow biofuel crops adds to the economic and environmental costs of biomass production. Biological nitrogen fixation provides an alternative, eco-friendly source of nitrogen for leguminous plants and some nonlegumes. With the objective of characterizing and eventually harnessing nitrogen-fixing bacteria in switchgrass roots, we assayed nitrogenase activity and surveyed nif $\mathrm{H}$-expressing bacteria in roots of switchgrass grown under agricultural conditions. Plants were cultivated at two separate locations in Oklahoma in different soil types for 5 years with three nitrogen fertilizer regimes $\left(0,90\right.$, and $180 \mathrm{~kg}$ of $\mathrm{N} \mathrm{ha}^{-1}$ year $\left.^{-1}\right)$. Nitrogenase activity associated with roots cleaned of soil was found to be highest in plants grown with no $\mathrm{N}$ fertilizer and lowest or not detectable for plants grown at the highest level of $\mathrm{N}$ fertilizer. A total of 454 abundant nif $\mathrm{H}$ operational taxonomic units (OTUs) were identified in the switchgrass roots. Diversity analysis of active nif $\mathrm{H}$ expressing bacteria showed that the most common orders were Burkholderiales (171 OTUs), Desulfovibrionales (55 OTUs), and Rhizobiales (44 OTUs). OTUs belonging to Azonexus, Pseudacidovorax, Desulfovibrio, Dechloromonas, and Bradyrhizobium were enriched in roots of plants grown under low nitrogen conditions. Analysis of significant OTUs showed distinct nifH-expressing microbial communities at the two field locations, as well as a unique community in roots of unfertilized soil at Frederick that exhibited the highest rates of nitrogen fixation.

Keywords: acetylene reduction, bacterial diversity, endophyte, metagenomics, microorganism, nif $\mathrm{H}$, nitrogenase, nutrient cycling, rhizosphere and phyllosphere, transcriptomics
${ }^{\dagger}$ Corresponding author: M. K. Udvardi: mudvardi@noble.org

First and second authors contributed equally.

Current address of R. A. Bahulikar: BAIF Development Research Foundation Central Research Station, Kamdhenu Nagar, Uralikanchan, Pune, India.

Current address of J. Mosali: Redbud Technologies Inc., Texas, U.S.A.

Funding: This work was supported by the U.S. Department of Energy Office of Biological and Environmental Research, through the Center for Bioenergy Innovation, and the Noble Research Institute. This research was also supported by the endowment associated with the Giles Professorship in the Department of Genetics at the University of Georgia.

*The $\boldsymbol{e}$-Xtra logo stands for "electronic extra" and indicates that two supplementary figures, two supplementary tables, and one supplementary data file are published online.

The author(s) declare no conflict of interest.
Switchgrass (Panicum virgatum $\mathrm{L}$.) is a warm season, $\mathrm{C}_{4}$-grass native to the tallgrass prairies of North America that has been targeted for development as a bioenergy crop (Goldemberg 2007). Switchgrass is a perennial that is adapted to diverse edaphic and climate conditions over a wide geographic range, which makes it an attractive choice for cultivation on marginal lands that are unsuitable for growing food crops (Mitchell et al. 2008; Varvel et al. 2008). Moreover, switchgrass has high biomass production potential. Once established, swards of switchgrass will remain productive for decades and can be harvested multiple times each year (Guretzky et al. 2010; Lemus et al. 2008). Although switchgrass does not always respond positively to nitrogen fertilizer (Fike et al. 2017), studies in several locations show that switchgrass growth responds positively to up to $180 \mathrm{~kg}$ of nitrogen $(\mathrm{N})$ fertilizer per hectare per year (Haque et al. 2009; Guretzky et al. 2010; Lemus et al. 2008). However, application of $\mathrm{N}$ fertilizer increases production costs, reduces the energy balance of biomass production, and can harm the environment through the release of $\mathrm{N}$-containing 
gases to the atmosphere and $\mathrm{N}$ solutes to water systems (Abrol et al. 2012). Although switchgrass can be grown and harvested over multiple years in fields with no $\mathrm{N}$ fertilizer input, biomass yields under these conditions tend to be relatively low (Guretzky et al. 2010; Lemus et al. 2008).

One potential source of $\mathrm{N}$ for switchgrass in native or farmed soils is prokaryotic nitrogen fixation, which is catalyzed by the enzyme nitrogenase. Nitrogenase activity has been detected in the rhizosphere of switchgrass and other prairie grasses, using the acetylene reduction assay (Tjepkema 1975; Tjepkema and Burris 1976). Recently, isotopic ( $\left.{ }^{15} \mathrm{~N}\right)$ evidence for episodic nitrogen fixation in field-grown switchgrass has also been obtained (Roley et al. 2019). However, little is known about the environmental factors that control nitrogen fixation rates in grasses in agricultural settings. Many bacteria and Archaea have the ability to reduce atmospheric dinitrogen to ammonia, via the nitrogenase enzyme complex encoded by three genes: nif $\mathrm{H}$, nif $\mathrm{D}$, and nif $\mathrm{K}$ (Dixon and Kahn 2004). Previous studies have shown high degrees of sequence similarity between nitrogenase gene sequences from various microorganisms, which enables polymerase chain reaction (PCR) amplification of nif genes and transcripts (cDNA) from most organisms using oligonucleotides that prime on conserved sequences (Zani et al. 2000). Sequences of nif transcripts associated with plants provide insight into potential source(s) of nitrogen for these plants.

Nitrogen-fixing bacteria (NFB) have been found to associate with several graminaceous food crops, including maize (Alves et al. 2006), rice (Knauth et al. 2005; Sessitsch et al. 2012), and sugarcane (Boddey 1995; Boddey et al. 2003; Burbano et al. 2011), as well as such bioenergy crops as Miscanthus, Spartina, and Pennisetum (Kirchhof et al. 1997). Diverse bacteria possessing nitrogenase (nif) genes have also been associated with switchgrass (Bahulikar et al. 2014; Roley et al. 2019).

As part of our efforts to develop effective nitrogen-fixing endophytes of switchgrass, we sequenced and characterized the diversity of nif $\mathrm{H}$ gene transcripts associated with roots of switchgrass plants grown for 5 years at two distinct field sites in Oklahoma with different soil type and varying levels of $\mathrm{N}$ fertilization. Although diazotrophs were found in all root samples, nitrogen fixation activity was largely confined to roots of $\mathrm{N}$-deprived plants.

\section{MATERIALS AND METHODS}

Plant material. Switchgrass (Panicum virgatum 'Alamo') plants were sampled from two experimental field sites in Oklahoma, one near Frederick $\left(34^{\circ} 23^{\prime} \mathrm{N} ; 98^{\circ} 85^{\prime} \mathrm{W}\right)$ and the other near Burneyville $\left(33^{\circ} 89^{\prime} \mathrm{N} ; 97^{\circ} 29^{\prime} \mathrm{W}\right)$. Frederick soil is a Foard silt loam type (fine, smectitic, thermic Vertic Natrustolls, $\mathrm{pH} 8.2,1.9$ to $2.4 \%$ organic matter, 8 to $56 \mathrm{mg}$ of $\mathrm{P} \mathrm{kg}^{-1}$, and 306 to $530 \mathrm{mg} \mathrm{of} \mathrm{K} \mathrm{kg}^{-1}$ ) and Burneyville soil is a Minco fine sandy loam (coarse-silty, mixed, superactive, thermic Udic Haplustolls, $\mathrm{pH} 6.6,1.0 \%$ organic matter, $33 \mathrm{mg}$ of $\mathrm{P} \mathrm{kg}^{-1}$, and $172 \mathrm{mg}$ of $\mathrm{K} \mathrm{kg}^{-1}$ ). Switchgrass was planted on 19 May and 21 May 2007, in Burneyville and Frederick, respectively, with two replicate plots grown for each nitrogen treatment. Plots were fertilized with ammonium nitrate at 0,90 , and $180 \mathrm{~kg}$ of $\mathrm{N} \mathrm{ha}^{-1}$ year $^{-1}$, as described previously (Guretzky et al. 2010). Phosphorus and $\mathrm{K}$ were applied across all plots as triple superphosphate (0-46-0) at $67.2 \mathrm{~kg} \mathrm{ha}^{-1}\left(14 \mathrm{~kg}\right.$ of $\left.\mathrm{P} \mathrm{ha}^{-1}\right)$ and potassium chloride (0-0-60) at $134 \mathrm{~kg} \mathrm{ha}^{-1}\left(60 \mathrm{~kg}\right.$ of $\left.\mathrm{K} \mathrm{ha}^{-1}\right)$.

Sample preparation. Switchgrass root samples were harvested in June 2012. At least 10 plants per $N$ treatment were harvested randomly from each of the two sites. Plants were uprooted with a shovel and excess soil was removed from the roots by vigorous shaking. Plants were transported to the laboratory in clean plastic bags. On the same day, roots were thoroughly washed of soil under running tap water. A portion of each cleaned root system was assayed for acetylene reduction (nitrogenase) activity. Another portion was surface sterilized by treatment with $70 \%$ alcohol for 5 min followed by $10 \%$ sodium hypochlorite solution for $30 \mathrm{~min}$. Surface sterilized roots were rinsed three times with sterile deionized water and then stored at $-80^{\circ} \mathrm{C}$ until further use.

RNA extraction. Surface-sterilized root pieces were pulverized in liquid nitrogen using a cryo-mill (6870 Freezer Mill, SPEX SamplePrep). Total RNA was extracted from $100 \mathrm{mg}$ of pulverized tissue using an RNeasy Plant Minikit (Qiagen), following the manufacturer's instructions. Genomic DNA was removed from RNA samples by DNAse 1 treatment (Turbo DNAse, Ambion) and RNA was column-purified using an RNeasy MinElute Cleanup kit (Qiagen). RNA was quantified using a Nanodrop Spectrophotometer ND-100 (NanoDrop Technologies, Willington, DE) and evaluated for purity with a Bioanalyzer 2100 (Agilent, Santa Clara, CA). Checks for genomic DNA contamination of RNA were performed using nif $\mathrm{H}$ primers (details below) and 16S RNA gene primers 27F (Edwards et al. 1989) and 1492R (Weisburg et al. 1991).

Acetylene reduction assay. Nitrogenase activity associated with washed plant roots was measured using the acetylene reduction assay (Pedersen et al. 1978; Van Berkum and Sloger 1981). Briefly, approximately $1 \mathrm{~g}$ of roots ( $n=30$ per treatment and location) was placed in a $10-\mathrm{ml}$ glass tube containing $1 \mathrm{ml}$ of B\&D medium (Broughton and Dilworth 1971) with no nitrogen. Tubes were sealed with suba seals (Sigma). Pure bottled acetylene was injected by syringe to $10 \%$ by volume. Assays were conducted at room temperature in the dark. Ethylene production was measured after $24 \mathrm{~h}$ by injecting $100 \mu \mathrm{l}$ of gas from the assay tube into a gas chromatograph (GC; Agilent 7890A), with a HP-5 column, an oven temperature of $100^{\circ} \mathrm{C}$, and front inlet and FID detector temperatures of $62^{\circ} \mathrm{C}$ and $200^{\circ} \mathrm{C}$, respectively, as modified from Trinick et al. (1976). $\mathrm{N}_{2}$ was used as a carrier gas with a flow rate of $30 \mathrm{ml} / \mathrm{min}$. Roots incubated without acetylene served as negative controls to measure any endogenous ethylene production. After assay, roots were dried in an oven at $65^{\circ} \mathrm{C}$ for 2 days and then weighed. Serial dilutions of a known quantity of ethylene were used to make standard curves of GC chromatogram peak area in order to calculate the amount of ethylene produced in acetylene reduction assays. Nitrogenase activity was calculated as the amount of ethylene produced per unit root dry weight during the $24 \mathrm{~h}$ assay period.

Preparation of Illumina amplicon libraries and nif $\mathbf{H}$ clonal libraries from switchgrass RNA. Five hundred nanograms of each switchgrass RNA sample was used for first strand cDNA synthesis with the Superscript III system (Invitrogen Cat. no. 18080-051), using its random primer mix. The first strand cDNA reaction $(5 \mu \mathrm{l})$ and nif $\mathrm{H}$ primers (nif $\mathrm{H} 1$ and nif $\mathrm{H} 2$ ) were used to amplify partial nif $\mathrm{H}$ gene transcripts (Bahulikar et al. 2014; Zani et al. 2000). Five microliters of this PCR reaction was used as a template for nested $\mathrm{PCR}$ with the nif $\mathrm{H} 3$ and nif $\mathrm{H} 4$ primers (Zani et al. 2000; Bahulikar et al. 2014). For Illumina Miseq analysis, the sequence of the nif $\mathrm{H} 3$ primers includes Illumina adaptor (atgatacggcgaccaccgagatctacact ctttcct), 8 bp i5 barcode, i5 sequencing primers (acacgacgctcttcc gatct), and nif $\mathrm{H}$ gene-specific sequences. The sequence of nif $\mathrm{H} 4$ primer has Illumina adaptor (caagcagaagacggcatacgagat), 8 bp i7 barcode, i7 sequencing primers (gtgactggagttcagacgtgtgctcttccgat $\mathrm{ct}$ ), and nif $\mathrm{H}$ gene specific sequence. The nifH gene specific primers were described previously (Bahulikar et al. 2014). PCR products were purified with Sera-Mag Magnetic Beads (GE Life Sciences). After Picogreen quantification, an equal volume of each sample was pooled and subjected to paired-end Illumina sequencing (MiSeq, Georgia Genomics Facility, Athens, GA). Reverse 
transcriptase-free control reactions were included for verification of complete DNA digestion/removal during RNA extraction. An Illumina-MiSeq (PE300) run was performed on these library pools at the Georgia Genomics Facility (University of Georgia, Athens, GA).

Sequence datasets were trimmed, clustered and classified in MOTHUR 1.35 (Schloss et al. 2009). The MOTHUR program was also used for preclustering, distance calculations, clustering, and further analysis based on operational taxonomic units (OTUs). A distance matrix was generated from the resulting sequences. Sequences were clustered into OTUs using the farthest neighbor algorithm. We clustered OTUs at $92 \%$ similarity, which was found to be the optimal cut-off to cluster nif $\mathrm{H}$ sequences at the species level (Gaby et al. 2018). The nif $\mathrm{H}$ dataset was further analyzed by retaining abundant OTUs occurring more than three times. We further rarified abundant reads by subsampling 1,000 reads from each sample using the subsample function in MOTHUR. The nif $\mathrm{H}$ OTUs that were differentially expressed in different biological samples were identified using the linear discriminant analysis effect size (LefSe) method (Segata et al. 2011). LefSe determines the OTUs most likely to explain differences between treatments by coupling standard tests for statistical significance with additional tests that factor in biological constancy and relevance. Taxonomybased classification of nif $\mathrm{H}$ gene sequences was obtained from the database created from the reference sequences in the NCBI database and RDP FunGene database (Fish et al. 2013). Top hits from the BlastN search were imported into MEGAN for phylogenetic visualization (Huson et al. 2016).

The phylogeny of the abundant OTUs from Illumina analyses were further analyzed with MEGA software, version X (Kumar et al. 2016), using the minimum evolution method (Rzhetsky and Nei 1993).

\section{RESULTS}

Nitrogenase activity in roots of field-grown switchgrass. To determine whether biological nitrogen fixation is associated with field-grown switchgrass plants in Oklahoma, we took advantage of a 5-year-old sward of switchgrass that was cultivated to determine the impact of different levels of $\mathrm{N}$ fertilization on switchgrass biomass production (Guretzky et al. 2010). Acetylene reduction activity of washed roots was found to be highest in the roots of plants grown in soils with no added $\mathrm{N}$ fertilizer $(96.3 \pm 19.0$ and $32.1 \pm 8.8$ nmoles $\mathrm{g}^{-1} \mathrm{day}^{-1}$ for Frederick and Burneyville, respectively), with activity being low or undetectable in roots of plants receiving $180 \mathrm{~kg}$ of $\mathrm{N} \mathrm{ha}^{-1}$ in Frederick $(2.6 \pm 1.1$ nmoles $\mathrm{g}^{-1}$ day $\left.^{-1}\right)$ and Burneyville $\left(0\right.$ nmoles $\mathrm{g}^{-1}$ day $\left.^{-1}\right)$ (Fig. 1). Nitrogenase activity of excised roots decreased with increasing rates of $\mathrm{N}$ fertilizer application. Higher acetylene reduction rates were measured in roots of plants from Frederick than from Burneyville at each of the $\mathrm{N}$ fertilizer levels (Fig. 1). No ethylene, the product of acetylene reduction by nitrogenase, was observed from switchgrass roots in the absence of acetylene, indicating that any background plant production of this phytohormone was below the detection limit of these assays.

Diversity and abundance of nif $\mathrm{H}$ transcripts in the switchgrass root endosphere. A total of 188,847 nif $\mathrm{H}$ sequences were obtained after initial demultiplexing and assembly. Filtering to remove chimeric sequences and sequences present less than three times, and clustering of sequences with at least $92 \%$ similarity, yielded 454 OTUs belonging to 42 genera. The 50 most abundant OTUs accounted for $75 \%$ of all sequences. The presence and abundance of different genera were assessed by taxonomic assignment of all sequences using a custom database by combining the identified nif $\mathrm{H}$ sequences from the FunGene database of the
Ribosomal Database Project and NCBI GenBank. The most common orders were Burkholderiales (171 OTUs), Desulfovibrionales (55 OTUs), and Rhizobiales (44 OTUs). Abundant OTU classes included members of Betaproteobacteria (Azonexus [23.8\%], Pseudacidovorax [20\%], Rubrivivax [7\%], Ideonella [5.5\%], Dechloromonas [5.2\%], Burkholderia [3.5\%], Pelomonas [1.5\%], and Azoarcus [1.1\%]), Alphaproteobacteria (Bradyrhizobium [3.7\%] and Azorhizobium [1.3\%]), and Deltaproteobacteria (Desulfovibrio [13.8\%]). Abundant OTUs were also found for Bacillus (1.3\%) and Spirochaeta (0.6\%), members of the Firmicutes and Spirochetes, respectively (Supplementary Table S1).

Shannon diversity indices showed that OTU diversity was higher in Frederick than in Burneyville samples (Fig. 2A). Rarefaction curves showed that most of the Burneyville samples plateaued at the current level of sampling (Fig. 2B). In contrast, the curves derived from Frederick samples did not plateau with 1,000 subsampled sequences (Fig. 2C). This result also points to higher diversity in Frederick samples than in Burneyville samples.

Multivariate statistical analysis was performed to compare the overall population structure of the nif $\mathrm{H}$-expressing microbiome at both locations and different levels of nitrogen fertilization. PCoA analysis using the switchgrass OTU table (Supplementary Table S2), showed only location-dependent clustering. A nonparametric analysis of molecular variance (AMOVA) was also performed to test for significant differences in the nif $\mathrm{H}$ OTU diversity between treatments (i.e., location and level of nitrogen fertilization). The analysis revealed statistically-significant differences in OTU diversity between locations ( $P$ value 0.001$)$, but not between the various $\mathrm{N}$ treatments (Fig. 3).

Next, we explored the numbers of OTUs unique to, or shared between, roots exposed to different nitrogen levels (Fig. 4). A total of 403 OTUs were found in Burneyville samples and 425 OTUs were found in Frederick samples. In Burneyville samples, 86 OTUs were present at all three nitrogen levels, whereas 59 OTUs were specific to switchgrass root samples collected from the field that received no $\mathrm{N}$ fertilizer (Fig. 4A). In Frederick samples, 205 OTUs

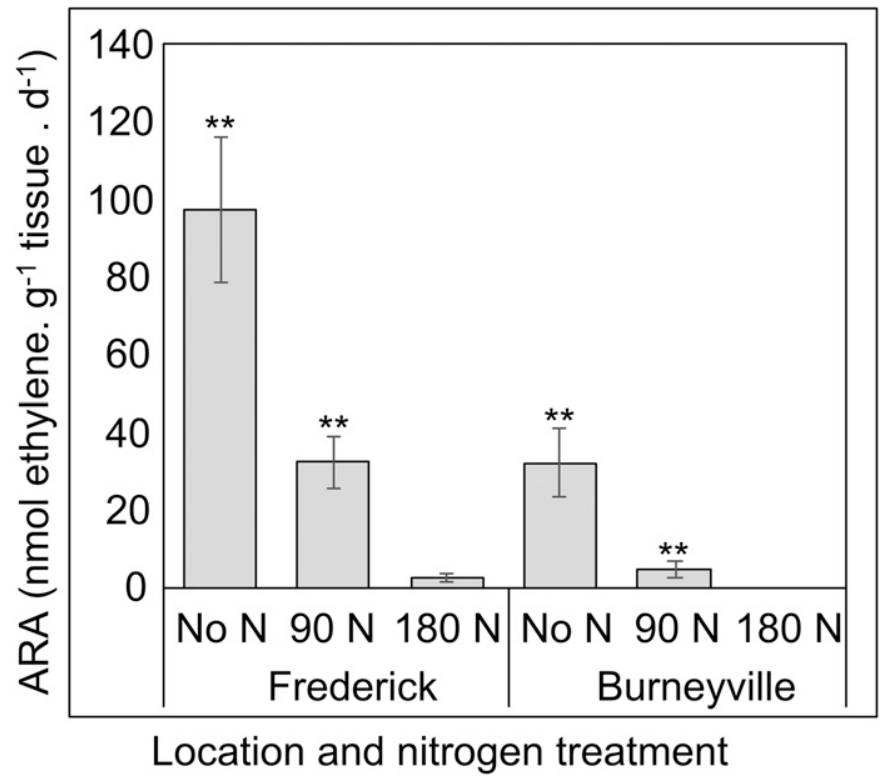

Fig. 1. Nitrogenase activity of switchgrass roots. Acetylene reduction activity (ARA) of nitrogenase was measured for roots isolated from plants grown in agricultural fields near Frederick and Burneyville, OK, after 5 years of growth with 0,90 , or $180 \mathrm{~kg}$ of $\mathrm{N}$ supplied as ammonium nitrate each year. $n=30,{ }^{\star \star} P<0.01$, error bars represent standard deviation. 



Fig. 2. Alpha diversity analysis of nif $\mathrm{H}$ operational taxonomic units (OTUs) of switchgrass roots. A, The richness of nifH OTUs was assessed using the Shannon diversity index. Horizontal lines within the boxes represent medians. Tops and bottoms of the boxes represent 75th and 25th quartiles. The upper and lower bars extend to maximum and minimum values in each dataset. Rarefaction analyses of nif $\mathrm{H}$ OTUs in B, Burneyville samples and C, Frederick samples, clustered at $92 \%$ similarity. Burneyville samples from high, medium, and low nitrogen fields are labeled BHN, BMN, and BLN, respectively. Likewise, Frederick samples from high, medium, and low nitrogen fields are labeled FHN, FMN, and FLN, respectively. B, Burneyville; F, Frederick; $\mathrm{H}$, high; M, medium; L, low; and $\mathrm{N}$, nitrogen. were present at all tested nitrogen levels, and 36 OTUs were specific to the no added-N treatment (Fig. 4B).

Representative sequences of nif $\mathrm{H}$ OTUs were used to search for the closest homologs in the NCBI-NR database. The top NCBIBLAST hits were used to construct a phylogenetic tree with MEGAN software (Fig. 5). In all, 75 OTUs out of 454 OTUs did not have homologs in the NCBI database and were not included in the analysis. The phylogenetic tree based on 379 OTUs returned 42 genera. The dominant genera were Pseudacidovorax (77 OTUs), Desulfovibrio (55 OTUs), Rubrivivax (34 OTUs), Bradyrhizobium (25 OTUs), Ideonella (23 OTUs), Dechloromonas (12 OTUs), Azonexus (12 OTUs), and Paraburkholderia (15 OTUs). Phylogenetic analysis of 77 OTUs homologous to Pseudacidovorax intermedius showed that there is substantial diversity within this genus (Supplementary Fig. S1). The phylogenetic analysis of unassigned OTUs together with their closest homolog in the NCBINR database revealed that most of these likely belong to Burkholdariales, Rhizobiales, and Desulfovibrionales. Some of these nif $\mathrm{H}$ OTUs appear to represent new genera (e.g., Clades 1, 11, and 12 in Supplementary Fig. S2).

We conducted LefSe analysis to identify OTUs that showed statistically significant differences $(P<0.01)$ in transcript abundance between different nitrogen levels at each location. Hierarchical clustering of nif $\mathrm{H}$ expression patterns of the diazotrophic "community" of each sample resulted in two major clusters, A and B, largely reflecting the two sites of collection, Burneyville and Frederick, respectively. Interestingly, given their relatively high levels of nitrogenase activity, root samples collected from low-N fields of Frederick (FLN) appeared as a subcluster within the B

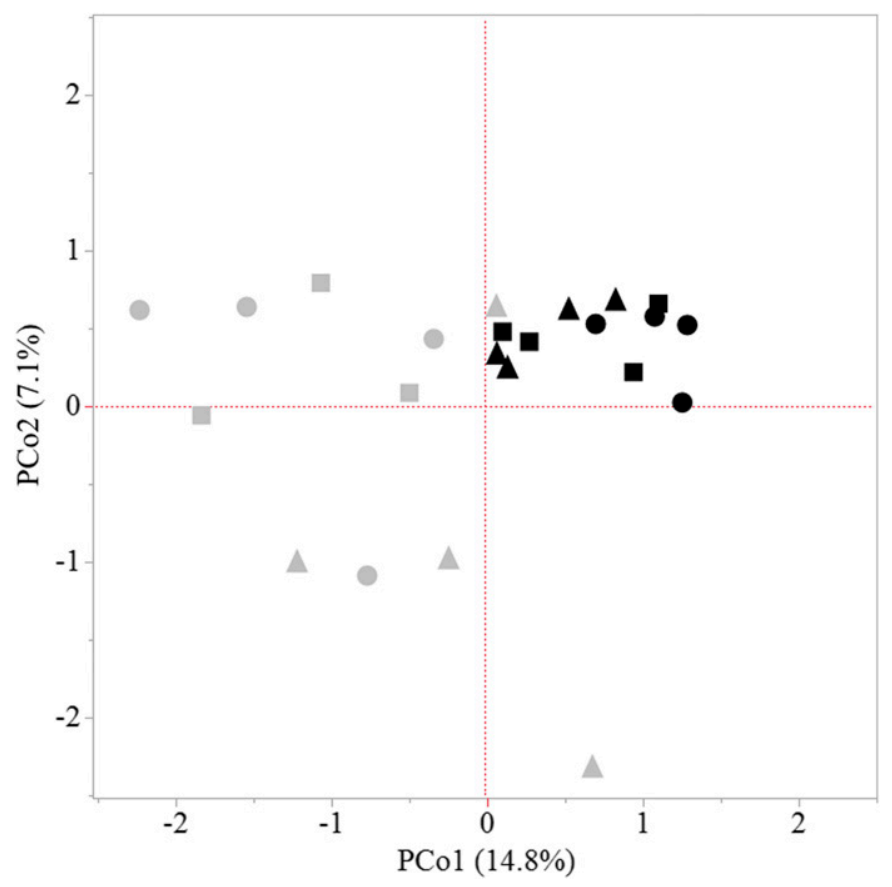

Fig. 3. Principal coordinates analysis (PCoA) of nif $\mathrm{H}$ operational taxonomic units (OTUs) from switchgrass roots. PCoA plots were generated from a distance matrix for the Jaccard indices set using the rarified nifH OTU table. Plots show the first two principal axes. Switchgrass samples from Burneyville are shown in gray, and Frederick samples are shown in black. Samples from the plots that received $180 \mathrm{~kg}$ of $\mathrm{N} \mathrm{ha}^{-1}$ year ${ }^{-1}$ are shown as squares, samples from plots with $90 \mathrm{~kg}$ of $\mathrm{N} \mathrm{ha}^{-1}$ year $^{-1}$ are shown as triangles and samples from plots with no added nitrogen are shown as circles. 


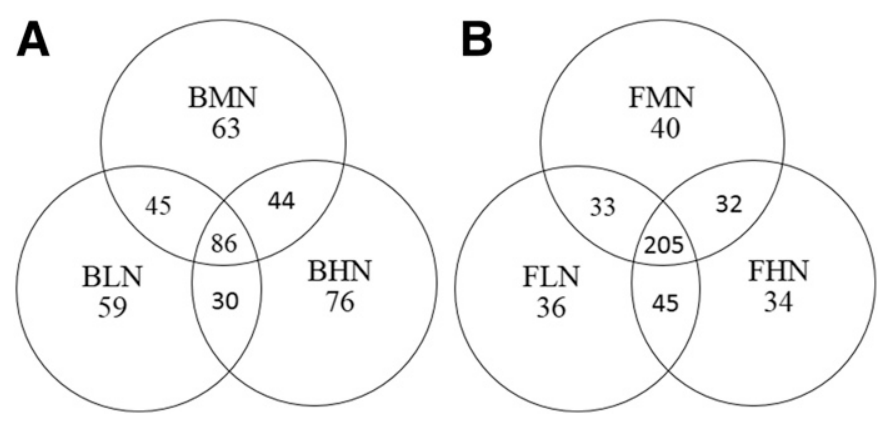

Fig. 4. Venn diagrams showing shared and unique operational taxonomic units from roots of switchgrass plants grown in A, Burneyville and $\mathbf{B}$, Frederick under different nitrogen regimes. Root samples $B H N, B M N$, and BLN were collected from high (180 N), medium $(90 \mathrm{~N})$, and low $(0 \mathrm{~N})$ nitrogen fields from Burneyville. Likewise, Frederick samples from high, medium, and low nitrogen fields are labeled FHN, FMN, and FLN, respectively. B, Burneyville; F, Frederick; H, high; M, medium; L, low; and $\mathrm{N}$, nitrogen. cluster (Fig. 6). Abbreviations: B, Burneyville; F, Frederick; H, high; M, medium; L, low; and $\mathrm{N}$, nitrogen.

\section{DISCUSSION}

Switchgrass grows quite well in some soils without added nitrogen fertilizer, although biomass yields of unfertilized plants are generally lower than those of plants that receive $\mathrm{N}$ fertilizer, at least in Oklahoma (e.g., 10.4 versus $15.5 \mathrm{t} \mathrm{ha}^{-1}$ year $^{-1}$ at 0 versus $180 \mathrm{~kg}$ $\mathrm{N} \mathrm{ha}^{-1}$, respectively; Guretzky et al. 2010). In a previous study of the switchgrass plantations used in the current study, plant shoots removed $40 \mathrm{~kg}$ of N ha ${ }^{-1}$ year ${ }^{-1}$ from unfertilized plots (Guretzky et al. 2010), indicating that alternative sources of $\mathrm{N}$ were available to the plants, including pre-existing soil-N, fixed-N deposited from the atmosphere, and/or biological nitrogen fixation. Here, we present evidence that biological nitrogen fixation occurs in the roots of switchgrass plants grown in fields without $\mathrm{N}$ fertilizer for 5 years, consistent with the notion that associative nitrogen fixation (ANF) was one source of $\mathrm{N}$ for these plants. Recently, ${ }^{15} \mathrm{~N}$-isotopic evidence was obtained for episodic nitrogen fixation on switchgrass roots and surrounding soil (Roley et al. 2019), confirmation that ANF is a significant source of $\mathrm{N}$ for switchgrass under certain conditions. While environmental effects on ANF, which may

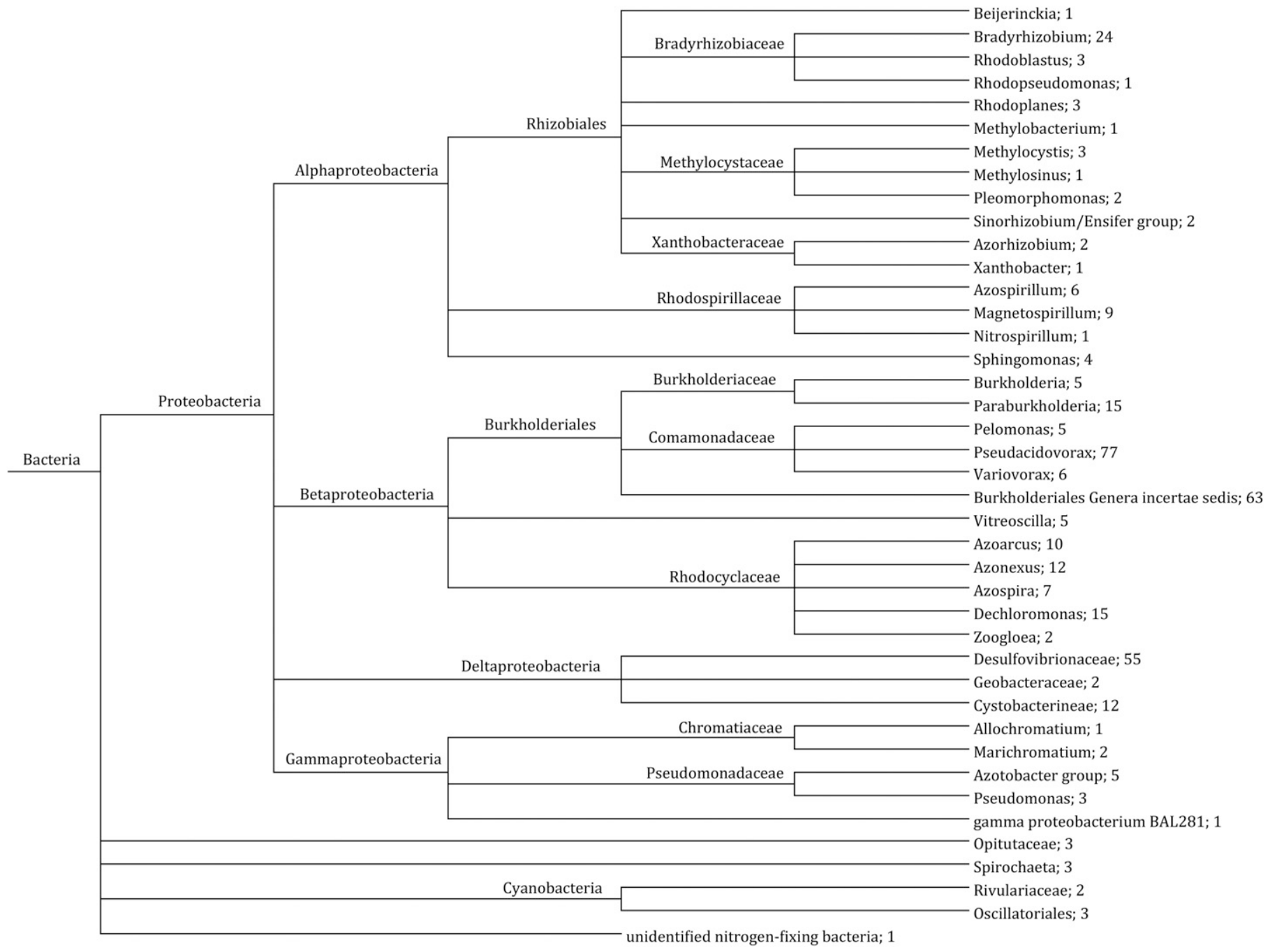

Fig. 5. Phylogeny of nifH operational taxonomic units (OTUs) from the roots of switchgrass. MEGAN analysis (Huson et al. 2016) of representative sequences for each of the 379 nifH OTUs, based on a BLASTN comparison with NCBI-NR. The number of OTUs that are homologous to each taxon are shown after the semicolon. 
include water, oxygen, and/or nutrient availability (Smercina et al. 2019), were not determined in the previous study, it appeared that ANF was independent of the developmental stage of plants (Roley et al. 2019). In the present study, we found evidence that soil type (i.e., location) and $\mathrm{N}$ fertilizer inputs (i.e., soil-N) affect ANF on switchgrass roots.

Using the acetylene reduction assay to measure nitrogenase activity, we found highest activity in roots of plants that received no fertilizer nitrogen for the 5 years before sampling. Nitrogenase activity was low in roots of plants that received moderate levels of $\mathrm{N}$ fertilizer each year, while little or no activity was associated with roots of plants exposed to high $\mathrm{N}$. These results are consistent with the fact that energy-intensive nitrogen fixation by diazotrophs is repressed when alternative $\mathrm{N}$ compounds are freely available in the environment (Burris and Roberts 1993; Dixon and Kahn 2004; Kessler et al. 2001; Rao et al. 1982). A recent switchgrass study found that $\mathrm{N}$ fertilizer addition to soil reduced the ability of rootassociated diazotrophs to activate nitrogen fixation over several days in the presence of added sugar as substrate for bacterial metabolism and growth (Roley et al. 2018).

We found higher nitrogenase activity in roots of plants from Frederick than in those from Burneyville, which is approximately
$200 \mathrm{~km}$ east of Frederick. Apart from differences in soil type and $\mathrm{pH}$, Frederick receives less rainfall, on average, than does Burneyville. However, Frederick soil had a higher organic-C content and probably higher water-holding capacity than soil of Burneyville (Guretzky et al. 2010). Both of these factors have been positively correlated with biological nitrogen fixation (Sall and Sinclair 1991; Smercina et al. 2019), so it is tempting to speculate that they may have contributed to higher ANF on switchgrass roots from Frederick compared with those of Burneyville, with root exudate and/or stored bacterial carbon compounds sufficing to maintain higher nitrogen fixation on Frederick roots after the removal of soil.

The dinitrogenase reductase gene, nif $\mathrm{H}$, has been used by many researchers to study the diversity and potential nitrogen-fixing activity of diazotrophs in various environments (Zehr et al. 1995; Martensson et al. 2009; Burbano et al. 2011; Lema et al. 2012). We used nif $\mathrm{H}$ transcript sequences to identify and classify putative nitrogen-fixing endophytes and to gain insight into the potential contribution of each to ANF. Our analysis identified 454 OTUs belonging to 42 genera. The composition of the nif $\mathrm{H}-$ expressing fraction of the root microbiome was significantly different between the Burneyville and Frederick samples. Members of

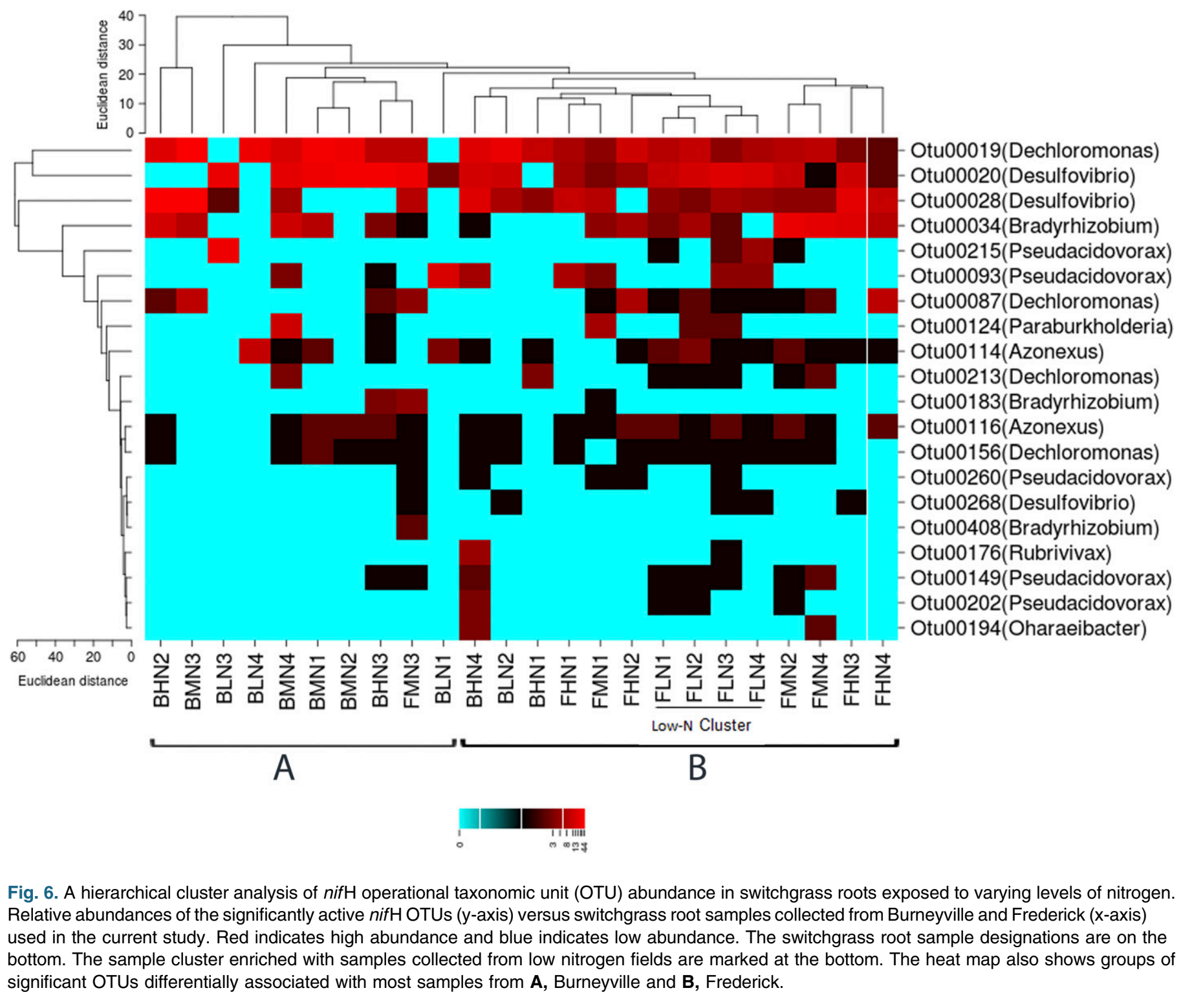


orders Burkholderiales (e.g., Burkholderia, Paraburkholderia, Pelomonas, Pseudacidovorax, Ideonella, Variovorex, Leptothrix, and Rubrivivax), Rhodocyclales (e.g., Azonexus, Dechloromonas, and Azoarcus), Rhizobiales (e.g., Bradyrhizobium sp.), and Desulfovibrionales (Desulfovibrio) were abundant in switchgrass roots under all nitrogen conditions. Members of most of these genera are known to colonize grasses endophytically and to fix nitrogen (Chowdhury et al. 2007; Elbeltagy et al. 2001; Hara et al. 2019; Santi et al. 2013; Wang et al. 2015). In a previous study, Burkholderia OTUs were found to be abundant in the roots of switchgrass from native prairie (Bahulikar et al. 2014). Burkholderia phytofirmans was shown to colonize switchgrass roots and significantly promote growth of switchgrass cultivar Alamo under in vitro, growth chamber, and greenhouse conditions (Kim et al. 2012; Lowman et al. 2015). When the plasmid with nitrogenfixing genes from Burkholderia phymatum STM 815 was transferred to Burkholderia phytofirmans, the recipient was able to fix nitrogen in the roots of switchgrass (Lowman et al. 2015).

The nif $\mathrm{H}$ metatranscriptome analysis presented here indicates that Azonexus is the most dominant nif $\mathrm{H}$-expressing genus in switchgrass roots. The genus Azonexus is a member of the family Rhodocyclaceae in the class Betaproteobacteria and encompasses gram-negative, non-spore-forming, highly motile, and slightly curved rods (Chou et al. 2008). Members of the genus Azonexus are known grass root endophytes, which were initially included in the genus Azoarcus sensu lato along with the genera Azovibrio and Azospira (Reinhold-Hurek and Hurek 2000). Many members of these genera are diazotrophic endophytes of roots, and are more widespread than previously thought (Reinhold-Hurek and Hurek 2007). The relative abundance of Azonexus sp., one of the most abundant root endophytes of rice, was significantly reduced within the rice root in the presence of urea- $\mathrm{N}$ fertilizer and biofertilizer treatments (Jha et al. 2019).

Pseudacidovorax intermedius was the second most dominant nif $\mathrm{H}$-expressing taxon in switchgrass roots. Pseudacidovorax intermedius is a gram-negative bacterium belonging to the order Burkholderiales and family Comamonadaceae. It has been isolated from soil (Kampfer et al. 2008), rhizosphere and endophytic compartments of roots (Monteiro et al. 2011). The family Comamonadaceae continues to be enlarged with new genera and species, currently comprising over 100 species in 29 genera (Nguyen et al. 2018; Willems 2014). Our analysis showed extensive diversity among OTUs homologous to Pseudacidovorax sp. in general, including the discovery of apparently new genera, with some enrichment in switchgrass roots from low-N conditions. Thus, it would be interesting to assess the nitrogen-fixing activity of isolated strains of this genus under controlledinoculation conditions.

In many cases, specific microbial community services can be provided by a range of different microbes, but interactions will be preferred between specific partners in specific groups (Tshikantwa et al. 2018). For instance, we previously observed unique bacterial communities that differentiated the endophytic landscapes of domesticated versus wild species of the panicoid grass Setaria (Chaluvadi and Bennetzen 2018). Similarly, we found a distinct nif $\mathrm{H}$-expressing community in switchgrass root samples from the low-N field at Frederick (Fig. 6). The diazotrophs in this community included members of Pseudacidovorax, Desulfovibrio, Dechloromonas, and Bradyrhizobium. Given their distinct association with switchgrass roots under conditions conducive to ANF, it would be interesting to test individual isolates or consortia assembled with species belonging to these genera on axenic switchgrass to assess their individual or combined ability to fix nitrogen and to supply it to plants.
Finally, the nif $\mathrm{H}$ metatranscriptome analysis presented herein was based upon sequences of RT-PCR products derived from a set of nested degenerate primers that likely amplified different nif $\mathrm{H}$ sequences with different efficiencies. Therefore, the true diversity of nif $\mathrm{H}$ sequences in each sample may be underestimated. Furthermore, the number of sequences assigned to each OTU may not reflect the actual relative amounts of transcript from each gene or OTU in a given biological sample. For these reasons, we have refrained from drawing conclusions about the relative abundances of different nif $\mathrm{H}$ transcripts within a biological sample, and we advise caution in interpreting the results of diversity analysis of OTUs within or between samples for any similar study.

Conclusions. Nitrogen fixation was found to be associated with switchgrass plants grown for multiple years at two field sites in Oklahoma. Higher levels of $\mathrm{N}$ fertilization resulted in lower levels of ANF in roots, with the highest level of $\mathrm{N}$ fertilization $(180 \mathrm{~kg}$ $\mathrm{ha}^{-1}$ year $^{-1}$ ) essentially abolishing ANF. Metatranscriptomic analysis revealed diverse sets of diazotrophs associated with switchgrass roots, with enrichment of a subset of diazotrophs in roots of $\mathrm{N}$-deprived plants that exhibited the highest rates of nitrogen fixation. Such diazotrophs represent interesting targets for isolation and future development of bacterial strains to enhance switchgrass growth under low-input nutrient conditions, via ANF.

\section{ACKNOWLEDGMENTS}

We thank the Genomics Core Facility of The Noble Foundation and the Georgia Genomics Facility for sequencing nif $\mathrm{H}$ libraries. Illumina sequence data are deposited in the NCBI GenBank (Bioproject ID PRJNA560244).

\section{LITERATURE CITED}

Abrol, Y. P., Pandey, R., Raghuram, N., and Ahmad, A. 2012. Nitrogen cycle sustainability and sustainable technologies for nitrogen fertilizer and energy management. J. Indian Inst. Sci. 92:17-36.

Alves, B. J. R., Zotarelli, L., Fernandes, F. M., Heckler, J. C., De Macedo, R. T., Boddey, R. M., Jantalia, C. P., and Urquiaga, S. 2006. Biological nitrogen fixation and nitrogen fertilizer on the nitrogen balance of soybean, maize and cotton. Pesqui. Agropecu. Bras. 41:449-456.

Bahulikar, R. A., Torres-Jerez, I., Worley, E., Craven, K., and Udvardi, M. K. 2014. Diversity of nitrogen-fixing bacteria associated with switchgrass in the native tall-grass prairie of northern Oklahoma. Appl. Environ. Microbiol. 80: 5636-5643.

Boddey, R. M. 1995. Biological nitrogen fixation in sugar cane: A key to energetically viable biofuel production. Crit. Rev. Plant Sci. 14:263-279.

Boddey, R. M., Urquiaga, S., Alves, B. J. R., and Reis, V. 2003. Endophytic nitrogen fixation in sugarcane: Present knowledge and future applications. Plant Soil 252:139-149.

Broughton, W. J., and Dilworth, M. J. 1971. Control of leghemoglobin synthesis in snake beans. Biochem. J. 125:1075-1080.

Burbano, C. S., Liu, Y., Rosner, K. L., Reis, V. M., Caballero-Mellado, J., Reinhold-Hurek, B., and Hurek, T. 2011. Predominant nif $\mathrm{H}$ transcript phylotypes related to Rhizobium rosettiformans in field-grown sugarcane plants and in Norway spruce. Environ. Microbiol. Rep. 3:383-389.

Burris, R. H., and Roberts, G. P. 1993. Biological nitrogen fixation. Annu. Rev. Nutr. 13:317-335

Chaluvadi, S., and Bennetzen, J. L. 2018. Species-associated differences in the belowground microbiomes of wild and domesticated Setaria. Front. Plant Sci. 9:1183.

Chou, J. H., Sr., Jiang, J. C., Cho, J., Song, M. C., and Lin, M. C. 2008. Azonexus hydrophilus sp. nov., a nifH gene-harbouring bacterium isolated from freshwater. Int. J. Syst. Evol. Microbiol. 58:946-951.

Chowdhury, S. P., Schmid, M., Hartmann, A., and Tripathi, A. K. 2007. Identification of diazotrophs in the culturable bacterial community associated with roots of Lasiurus sindicus, a perennial grass of Thar Desert, India. Microbiol. Ecol. 54:82-90.

Dixon, R., and Kahn, D. 2004. Genetic regulation of biological nitrogen fixation. Nat. Rev. Microbiol. 2:621-631. 
Edwards, U., Rogall, T., Blöcker, H., Emde, M., and Böttger, E. C. 1989. Isolation and direct complete nucleotide determination of entire genes. Characterization of a gene coding for 16S ribosomal RNA. Nucleic Acids Res. 17:7843-7853.

Elbeltagy, A., Nishioka, K., Sato, T., Suzuki, H., Ye, B., et al. 2001. Endophytic colonization and in planta nitrogen fixation by a Herbaspirillum sp. isolated from wild rice species. Appl. Environ. Microbiol. 67:5285-5293.

Fike, J. H., Pease, J. W., Owens, V. N., Farris, R. L., Hansen, J. L., Heaton, E. A., Hong, C. O., Mayton, H. S., Mitchell, R. B., and Viands, D. R. 2017. Switchgrass nitrogen response and estimated production costs on diverse sites. GCB Bioenergy 9:1526-1542.

Fish, J. A., Chai, B., Wang, Q., Sun, Y., Brown, C. T., et al. 2013. FunGene: The functional gene pipeline and repository. Front. Microbiol. 4:291.

Gaby, J. C., Rishishwar, L., Valderrama-Aguirre, L. C., Green, S. J., Valderrama-Aguirre, A., Jordan, I. K., and Kostka, J. E. 2018. Diazotroph community characterization via a high-throughput nif $\mathrm{H}$ amplicon sequencing and analysis pipeline. Appl. Environ. Microbiol. 84:e01512-e01517.

Goldemberg, J. 2007. Ethanol for a sustainable energy future. Science 315: 808-810.

Guretzky, J. A., Biermacher, J. T., Cook, B. J., Kering, M. K., and Mosali, J. 2010. Switchgrass for forage and bioenergy: Harvest and nitrogen rate effects on biomass yields and nutrient composition. Plant Soil 339:69-81.

Haque, M., Epplin, F. M., and Taliaferro, C. M. 2009. Nitrogen and harvest frequency effect on yield and cost for four perennial grasses. Agron. J. 101:1463-1469.

Hara, S., Morikawa, T., Wasai, S., Kasahara, Y., Koshiba, T., et al. 2019. Identification of nitrogen-fixing Bradyrhizobium associated with roots of field-grown sorghum by metagenome and proteome analyses. Front. Microbiol. 10:407.

Huson, D. H., Beier, S., Flade, I., Górska, A., El-Hadidi, M., et al. 2016. MEGAN community edition-Interactive exploration and analysis of largescale microbiome sequencing data. PLOS Comput. Biol. 12:e1004957.

Jha, P. N., Gomaa, A. B., Yanni, Y. G., El-Saadany, A. Y., Stedtfeld, T. M., et al. 2019. Alterations in the endophyte-enriched root-associated microbiome of rice receiving growth-promoting treatments of urea fertilizer and Rhizobium biofertilizer. Microbiol. Ecol. doi:10.1007/s00248-019-01406-7

Kampfer, P., Thummes, K., Chu, H. I., Tan, C. C., Arun, A. B., Chen, W. M., Lai, W. A., Shen, F. T., Rekha, P. D., and Young, C. C. 2008. Pseudacidovorax intermedius gen. nov., sp. nov., a novel nitrogen-fixing betaproteobacterium isolated from soil. Int. J. Syst. Evol. Microbiol. 58:491-495.

Kessler, P. S., Daniel, C., and Leigh, J. A. 2001. Ammonia switch-off of nitrogen fixation in the methanogenic archaeon Methanococcus maripaludis: Mechanistic features and requirement for the novel GlnB homologues, NifI1 and NifI2. J. Bacteriol. 183:882-889.

Kim, S., Lowman, S., Hou, G., Nowak, J., Flinn, B., and Mei, C. 2012. Growth promotion and colonization of switchgrass (Panicum virgatum) $\mathrm{cv}$. Alamo by bacterial endophyte Burkholderia phytofirmans strain PsJN. Biotechnol. Biofuels 5:37.

Kirchhof, G., Reis, V. M., Baldani, J. I., Eckert, B., Dobereiner, J., and Hartmann, A. 1997. Occurrence, physiological and molecular analysis of endophytic diazotrophic bacteria in gramineous energy plants. Plant Soil 194:45-55.

Knauth, S., Hurek, T., Brar, D., and Reinhold-Hurek, B. 2005. Influence of different Oryza cultivars on expression of nifH gene pools in roots of rice. Environ. Microbiol. 7:1725-1733.

Kumar, S., Stecher, G., and Tamura, K. 2016. MEGA7: Molecular evolutionary genetics analysis version 7.0 for bigger datasets. Mol. Biol. Evol. 33: 1870-1874.

Lema, K. A., Willis, B. L., and Bourne, D. G. 2012. Corals form characteristic associations with symbiotic nitrogen-fixing bacteria. Appl. Environ. Microbiol. 78:3136-3144.

Lemus, R., Parrish, D. J., and Abaye, O. 2008. Nitrogen-use dynamics in switchgrass grown for biomass. Bioenerg Res. 1:153-162.

Lowman, J. S., Lava-Chavez, A., Kim-Dura, S., Flinn, B., Nowak, J., et al. 2015. Switchgrass field performance on two soils as affected by bacterization of seedlings with Burkholderia phytofirmans strain PsJN. Bioenerg. Res. 8:440-449.

Martensson, L., Diez, B., Wartiainen, I., Zheng, W., El-Shehawy, R., and Rasmussen, U. 2009. Diazotrophic diversity, nifH gene expression and nitrogenase activity in a rice paddy field in Fujian, China. Plant Soil 325:207-218.

Mitchell, R., Vogel, K. P., and Sarath, G. 2008. Managing and enhancing switchgrass as a bioenergy feedstock. Biofuels Bioprod. Biorefin. 2:530-539.

Monteiro, J. M., Vollú, R. E., Coelho, M. R. R., Fonseca, A., Neto, S. C. G., and Seldin, L. 2011. Bacterial communities within the rhizosphere and roots of vetiver (Chrysopogon zizanioides (L.) Roberty) sampled at different growth stages. Eur. J. Soil Biol. 47:236-242.

Nguyen, T. M., Trinh, N. H., and Kim, J. 2018. Proposal of three novel species of soil bacteria, Variovorax ureilyticus, Variovorax rhizosphaerae, and
Variovorax robiniae, in the family Comamonadaceae. J. Microbiol. 56: 485-492.

Pedersen, W. L., Chakrabarty, K., Klucas, R. V., and Vidaver, A. K. 1978. Nitrogen fixation (acetylene reduction) associated with roots of winter wheat and sorghum in Nebraska. Appl. Environ. Microbiol. 35:129-135.

Rao, J. L. N., Prasad, J. S., and Rao, V. R. 1982. Rice rhizosphere nitrogen-fixation $\left(\mathrm{C}_{2} \mathrm{H}_{2}\right.$ reduction $)$ as influenced by nitrogen source. Curr. Sci. India 51:900-901.

Reinhold-Hurek, B., and Hurek, T. 2000. Reassessment of the taxonomic structure of the diazotrophic genus Azoarcus sensu lato and description of three new genera and new species, Azovibrio restrictus gen. nov., sp. nov., Azospira oryzae gen. nov., sp. nov. and Azonexus fungiphilus gen. nov., sp. nov. Int. J. Syst. Evol. Microbiol. 50:649-659.

Reinhold-Hurek, B., and Hurek, T. 2007. Endophytic associations of Azoarcus spp. Pages 191-210 in: Associative and Endophytic Nitrogen-fixing Bacteria and Cyanobacterial Associations. Springer, Dordrecht.

Roley, S. S., Duncan, D. S., Liang, D., Garoutte, A., Jackson, R. D., Tiedje, J. M., and Robertson, G. P. 2018. Associative nitrogen fixation (ANF) in switchgrass (Panicum virgatum) across a nitrogen input gradient. PLoS One 13:e0197320.

Roley, S. S., Xue, C., Hamilton, S. K., Tiedje, J. M., and Robertson, G. P. 2019. Isotopic evidence for episodic nitrogen fixation in switchgrass (Panicum virgatum L.). Soil Biol. Biochem. 129:90-98.

Rzhetsky, A., and Nei, M. 1993. Theoretical foundation of the minimumevolution method of phylogenetic inference. Mol. Biol. Evol. 10:1073-1095.

Sall, K., and Sinclair, T. R. 1991. Soybean genotypic differences in sensitivity of symbiotic nitrogen fixation to soil dehydration. Plant Soil 133:31-37.

Santi, C., Bogusz, D., and Franche, C. 2013. Biological nitrogen fixation in nonlegume plants. Ann. Bot. (Lond.) 111:743-767.

Schloss, P. D., Westcott, S. L., Ryabin, T., Hall, J. R., Hartmann, M., Hollister, E. B., Lesniewski, R. A., Oakley, B. B., Parks, D. H., Robinson, C. J., Sahl, J. W., Stres, B., Thallinger, G. G., Van Horn, D. J., and Weber, C. F. 2009. Introducing mothur: Open-source, platform-independent, communitysupported software for describing and comparing microbial communities. Appl. Environ. Microbiol. 75:7537-7541.

Segata, N., Izard, J., Waldron, L., Gevers, D., Miropolsky, L., Garrett, W. S., and Huttenhower, C. 2011. Metagenomic biomarker discovery and explanation. Genome Biol. 12:R60.

Sessitsch, A., Hardoim, P., Doering, J., Weilharter, A., Krause, A., Woyke, T., Mitter, B., Hauberg-Lotte, L., Friedrich, F., Rahalkar, M., Hurek, T., Sarkar, A., Bodrossy, L., Van Overbeek, L., Brar, D., Van Elsas, J. D., and ReinholdHurek, B. 2012. Functional characteristics of an endophyte community colonizing rice roots as revealed by metagenomic analysis. Mol. PlantMicrobe Interact. 25:28-36.

Smercina, D. N., Evans, S. E., Friesen, M. L., and Tiemann, L. K. 2019. To fix or not to fix: Controls on free-living nitrogen fixation in the rhizosphere. Appl. Environ. Microbiol. 85:e02546-18.

Tjepkema, J. 1975. Nitrogenase activity in the rhizosphere of Panicum virgatum. Soil Biol. Biochem. 7:179-180.

Tjepkema, J. D., and Burris, R. H. 1976. Nitrogenase activity associated with some Wisconsin prairie grasses. Plant Soil 45:81-94.

Trinick, M. J., Dilworth, M. J., and Grounds, M. 1976. Factors affecting the reduction of acetylene by root nodules of lupinus species. New Phytol. 77: 359-370.

Tshikantwa, T. S., Ullah, M. W., He, F., and Yang, G. 2018. Current trends and potential applications of microbial interactions for human welfare. Front. Microbiol. 9:1156.

Van Berkum, P., and Sloger, C. 1981. Comparing time course profiles of immediate acetylene reduction by grasses and legumes. Appl. Environ. Microbiol. 41:184-189.

Varvel, G. E., Vogel, K. P., Mitchell, R. B., Follett, R. F., and Kimble, J. M. 2008. Comparison of corn and switchgrass on marginal soils for bioenergy. Biomass Bioenergy 32:18-21.

Wang, B., Seiler, J. R., and Mei, C. 2015. Burkholderia phytofirmans strain PsJN advanced development and altered leaf level physiology of switchgrass. Biomass Bioenergy 83:493-500.

Weisburg, W. G., Barns, S. M., Pelletier, D. A., and Lane, D. J. 1991. 16S ribosomal DNA amplification for phylogenetic study. J. Bacteriol. 173:697-703.

Willems, A. 2014. The family Comamonadaceae. Pages 777-851 in: The Prokaryotes. Springer,Berlin, Heidelberg.

Zani, S., Mellon, M. T., Collier, J. L., and Zehr, J. P. 2000. Expression of nif H genes in natural microbial assemblages in Lake George, New York, detected by reverse transcriptase PCR. Appl. Environ. Microbiol. 66:3119-3124.

Zehr, J. P., Mellon, M., Braun, S., Litaker, W., Steppe, T., and Paerl, H. W. 1995. Diversity of heterotrophic nitrogen fixation genes in a marine cyanobacterial mat. Appl. Environ. Microbiol. 61:2527-2532. 